\title{
Maternal low birth weight and adverse perinatal outcomes: the 1982 Pelotas Birth Cohort Study, Brazil
}

\author{
Maria P. Vélez, ${ }^{1,2}$ Iná S. Santos, ${ }^{1}$ Alicia Matijasevich, ${ }^{1}$ Denise Gigante, ${ }^{1}$ \\ Helen Gonçalves, ${ }^{1}$ Fernando C. Barros, ${ }^{3}$ and Cesar G. Victora ${ }^{1}$
}

Suggested citation Vélez MP, Santos IS, Matijasevich A, Gigante D, Gonçalves H, Barros FC, et al. Maternal low birth weight and adverse perinatal outcomes: the 1982 Pelotas Birth Cohort Study, Brazil. Rev Panam Salud Publica. 2009;26(2):112-9.

ABSTRACT Objective. To explore the association between maternal low birth weight (LBW) and adverse perinatal outcomes and to discriminate between confounders and mediating factors of these associations in a population-based birth cohort of Southern Brazil.

Methods. Data from 794 female members of the 1982 Pelotas Birth Cohort Study known to have delivered a live-born singleton offspring up to December 2004 were analyzed. Maternal birth weights were recorded in 1982. The associations between maternal and offspring characteristics were estimated by Poisson regression. Confounding was tested for socioeconomic, demographic, and psychosocial factors. Maternal anthropometric characteristics and hypertensive diseases during pregnancy were considered mediating factors.

Results. An increase of 100 grams $(\mathrm{g})$ in mothers' birth weight predicted a gain of $21 \mathrm{~g}$ in their infants' birth weight (95\% confidence interval (CI) 13.0-29.0 g, P < 0.001). Maternal $L B W$ was associated with offspring LBW (prevalence ratio (PR) 2.28 (95\% CI 1.34-3.89), $\mathrm{P}=0.002)$, preterm birth (PR $1.78(95 \%$ CI 1.12-2.81), $\mathrm{P}=0.01)$, and small for gestational age (SGA) (PR 1.93 (95\% CI 1.14-3.26), $\mathrm{P}=0.01)$. A causal chain linking maternal LBW and offspring $S G A$ was mediated by maternal prepregnancy weight.

Conclusion. Offspring of young women born with $L B W$ are more likely to be $L B W$, preterm, and SGA. Public health strategies aimed at decreasing the frequency of LBW are necessary to reduce the perpetuation of adverse perinatal outcomes in later generations. The intermediate role of prepregnancy weight among LBW women opens a promising window to decreasing the prevalence of SGA in similar populations.

Key words Birth weight; cohort studies; infant, low birth weight; infant, premature; infant, small for gestational age; Brazil.

1 Centro de Pesquisas Epidemiológicas, Universidade Federal de Pelotas, Departamento de Medicina Social, Rua Marechal Deodoro, 1160 Bairro Centro, Pelotas RS 96020-220, Brazil.

2 CHU Sainte-Justine, 3175 Côte-Sainte-Catherine, Room 4986B, Montreal, Quebec H3T 1C5, Canada. Send correspondence and reprint requests to: Maria P. Vélez, CHU Sainte-Justine, 3175 CôteSainte-Catherine, Room 4986B, Montreal, Quebec H3T 1C5, Canada; telephone: +1 (514) 345-4931; fax: +1 (514) 345-2195; e-mail: mpvelez@gmail.com

3 Programa de Pós-graduação em Saúde e Comportamento, Universidade Católica de Pelotas, Rua Félix da Cunha 412 Bairro Centro, Pelotas 96010000, Brazil.
Low birth weight (LBW), a marker of preterm birth or intrauterine growth restriction, is associated with diseases such as hypertension, cardiovascular disease, stroke, and type 2 diabetes mellitus in adult life (1). Associations have also been recognized between birth weight and adverse reproductive health and pregnancy outcomes, including altered ovarian function, reduced fertility (2-5), gestational diabetes mellitus (6), and preeclampsia (7). Numerous investigators have also documented associations between maternal LBW and adverse events in the offspring such as LBW, preterm birth, and intrauterine growth restriction (8-21).

The mechanisms by which the mother's birth weight causes adverse effects in offspring are not well known. Many factors seem to act together: (1) adverse extrinsic environmental exposures that 
persist across generations, (2) adverse in utero exposures that stunt the mother's growth and possibly alter her metabolism, and (3) genetic attributes that manifest themselves similarly in mother and infant (22).

Although the associations between maternal LBW and adverse events in offspring have been widely studied, the mediating factors of these associations have not been investigated. Most previous studies in this field have treated potential mediators as confounding variables and simply adjusted for them instead of highlighting their impact. The mediator function of a third variable is defined as the generative mechanism through which the focal independent variable is able to influence the dependent variable of interest (23).

For a factor to be a mediator of maternal LBW and adverse outcomes in the offspring, two important statistical requirements must be satisfied (24). First, the mediating factor must have a sizeable etiological fraction (population attributable risk) for LBW; second, it must be more prevalent among the LBW mothers than in the non-LBW mothers.

In most of the studies concerning the intergenerational effect in birth weight, adjustments were made for infant sex and maternal anthropometric characteristics such as maternal height and prepregnancy weight; demographic and psychosocial factors such as maternal age, education, socioeconomic status, and marital status; maternal morbidity during pregnancy such as preeclampsia; toxic exposures such as smoking; and prenatal care such as number of prenatal care visits.

However, as stated by Kramer et al. for the study of socioeconomic disparities in pregnancy outcomes (24), we propose that anthropometric characteristics and maternal morbidity during pregnancy such as hypertensive diseases be considered mediating factors when studying the intergenerational effect in birth weight. First, maternal height and prepregnancy weight (25) as well as hypertensive diseases during pregnancy (26) are associated with offspring LBW. Second, several investigators have indicated that, although women who were born LBW catch up in growth during childhood, they continue to lag behind in growth compared with normal birth weight controls (27-31), although this association was not reproduced by Hack et al. (32). In addition, LBW women are at high risk of developing preeclampsia (7).
Data on socioeconomic, anthropometric, and additional biological factors from young adult parous females belonging to a population-based birth cohort from Southern Brazil offer an opportunity to study the intergenerational effects of LBW. Thus, the primary aim of this study was to evaluate the association between maternal LBW and the risk of adverse events in their offspring-specifically LBW, preterm birth, and small for gestational age (SGA) status - as well as to discriminate between confounders and mediating factors of these associations.

\section{MATERIALS AND METHODS}

\section{Study population}

Pelotas is a city in the extreme south of Brazil whose urban population grew from 214000 in 1982 to 320000 in 2000. The Pelotas Birth Cohort Study began in 1982 as a perinatal health survey assessing 5914 live-born infants (2 876 females) from the city's three maternity hospitals (accounting for more than $99 \%$ of all live births that year). Cohort members have been followed up and interviewed several times in subsequent years; methods used in follow-up phases of the cohort are described elsewhere (33).

This study analyzed data from 794 female singleton members of the original cohort known to have delivered a liveborn singleton up to December 2004. In the offspring generation, only the first live-born offspring were studied. This study used several data sources. Table 1 presents a summary of search strategies used to locate parous cohort members and sources of information.

\section{Data sources}

The first source of mother-offspring data came from a case-control study of adolescence parity within the cohort con-

TABLE 1. Year and source of data for parous women eligible for the study, Pelotas, Brazil, 2006

\begin{tabular}{lllr}
\hline Year & \multicolumn{1}{c}{ Study } & Selection/source & $n$ \\
\hline 2001 & $\begin{array}{l}\text { Adolescence pregnancy } \\
\text { case-control study }\end{array}$ & Parous adolescents identified up to March 2001 & 410 \\
$2001-2003$ & SINASC $^{\text {tracking }}$ & $\begin{array}{l}\text { SINASC records from April 2001 to December 2003 } \\
\text { linked to cohort women }\end{array}$ & 309 \\
2004 & $\begin{array}{l}\text { Pelotas 2004 Birth Cohort } \\
\text { Study }\end{array}$ & $\begin{array}{l}\text { Mother's name and age linked to original birth cohort } \\
\text { study }\end{array}$ & 75 \\
Total & & & 794
\end{tabular}

a SINASC, Sistema de Informações de Nascidos Vivos (Live Birth Information System-Brazil). ducted in 2001 (34). This study identified 446 parous women belonging to the 1982 cohort. They accounted for $16.2 \%$ of the original female cohort members (117 women who died between 1982 and 2001 were removed from the denominator). Among those identified, 3 refused to participate, and 23 could not be located, resulting in a sample of 420 parous women (94.2\% of those identified) who had delivered at least one live-born child up to March 31, 2001. Eight mother-offspring pairs were excluded from the analysis because five mothers and three offspring were twins. Two pairs were excluded because information on offspring birth weight was missing, leaving 410 motheroffspring pairs available for this study.

We searched the Live Birth Information System-Brazil (Sistema de Informações de Nascidos Vivos, SINASC) to identify female cohort members who delivered their firstborn singleton child between 31 March 2001 and 31 December 2003. In all, 312 women belonging to the cohort and their offspring were identified for the present study. We excluded three pairs because the mother was a twin, leaving 309 mother-offspring pairs.

In 2004, a new Pelotas Birth Cohort Study started (35). For the purpose of the present analysis, a matching procedure was performed linking the names of women giving birth in 2004 to the names of women pertaining to the 1982 cohort study. In this manner, 75 women belonging to the 1982 birth cohort and their offspring were identified.

\section{Measurement of variables}

Dependent variables were offspring birth weight in grams (g), LBW (birth weight $<2500 \mathrm{~g}$ ), preterm birth (gestational age $<37$ weeks), and SGA (below the 10th percentile of birth weight for gestational age and sex of the Williams curves). 
In the 2001 follow-up, offspring birth weight in grams and gestational age in weeks were collected from the antenatal registry card. In the antenatal registry card, gestational age is assigned taking into account the last normal menstrual period (LMP) and is confirmed by ultrasound examination if performed before 20 weeks of gestation. If both LMP and ultrasound dating were available and the two agreed within 7 days, we used the former to assign gestational age. If the two differed by more than 7 days, we used the ultrasound date. If the antenatal registry card was absent (25\%), birth weight and gestational age were collected by mother's recall.

In the SINASC data set, gestational age is registered by the delivery attendant in categories. In the perinatal study of the 2004 birth cohort, birth weight and gestational age were collected from the antenatal registry card. While in the hospital of delivery, all newborns were further examined by a trained fieldworker to estimate gestational age by the Dubowitz method, which is based on physical and neurological characteristics of the newborn (35). In the absence of both LMP and ultrasound information, clinical assessment of gestational age was used for the analysis (30\% in the current subsample). To standardize the three sources of information, offspring birth weight was analyzed as a continuous variable (birth weight in g) and LBW was analyzed as dichotomous (birth weight $<2500 \mathrm{~g}$, yes or no). Since gestational age was a categorical instead of a continuous variable in the SINASC, only preterm status was used for the analysis (gestational age $<37$ weeks, yes or no).

Concerning the independent variable maternal birth weight, newborns in 1982 were weighed with regularly calibrated pediatric scales (Filizolla, Brazil) to the nearest $10 \mathrm{~g}$.

Information was gathered on potential confounding or mediating factors according to a hierarchical framework (Figure 1). Adolescent status was defined as maternal age $<20$ years, skin color was defined by interviewer observation and was dichotomized as white or nonwhite, maternal education was categorized into less than eight years or at least eight years, and maternal cigarette smoking was categorized as smoker (one or more cigarettes per day in any trimester of pregnancy) or nonsmoker.

Monthly family income in Real was recorded at mother's birth and at off-

FIGURE 1. Hierarchical framework of analysis, Pelotas, Brazil, 2006

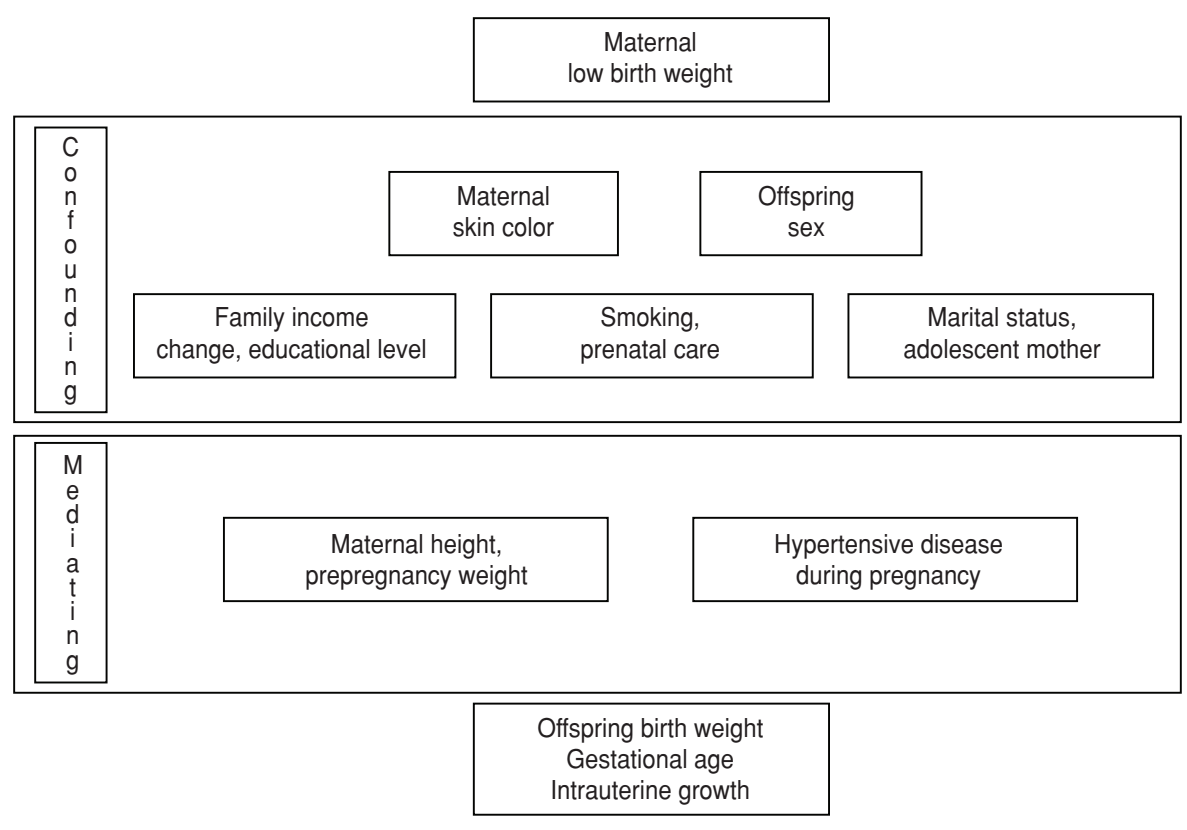

spring's birth. It was categorized as tertile of family income for each period. The lowest socioeconomic status was the inferior tertile (defined as poor). The middle and higher tertiles were defined as nonpoor. The variable "family income change" was created according to the trajectory of family income at the time of the offspring's birth relative to the mother's birth and was categorized as always poor, never poor, poor/nonpoor, or nonpoor/poor.

Anthropometric variables studied were maternal height and prepregnancy weight (24). Maternal height was measured in 2001 for mothers who delivered before 31 March and in 2004-2005 for mothers who delivered between 31 March 2001 and 31 December 2004. Prepregnancy weight in kilograms $(\mathrm{kg})$ was obtained from the antenatal registry card if available or by maternal recall at the interview. Height was dichotomized as $<1.50$ meters (m) and $\geq 1.50 \mathrm{~m}$. Hypertensive disease was defined as having a history of chronic hypertension, preeclampsia, or eclampsia during pregnancy.

\section{Statistical analysis}

The $\chi^{2}$ test was used to explore the associations between categorical variables. For continuous variables, simple linear regression was used. Correlation between birth weight in both generations was tested with Pearson's coefficient.
Multivariable linear regression was used for adjustment of continuous outcomes. For categorical outcomes, Poisson regression was used to express results in terms of rate ratios rather than odds ratios, which would overestimate the prevalence ratios (PR) because of the high prevalence of the outcomes in the studied population. Potential confounders and mediating factors of the association between maternal birth weight and offspring birth weight were evaluated according to a hierarchical approach (Figure 1). The choice of factors to be included in the adjusted analysis was based both on statistical associations as well as on a conceptual framework describing the hierarchical relationships among all risk factors studied. One regression equation was fitted in each hierarchical level. The first level included maternal skin color and offspring sex. Variables with a $P$ value $\leq 0.2$ were included in the next level of the analysis. The variables of the next levels were adjusted for others in the same or higher levels of the hierarchical model. Change of family income and educational level, smoking and prenatal care, and marital status and adolescent mother were in the second level. Maternal anthropometric characteristics (height and prepregnancy weight) as well as hypertensive diseases during pregnancy were considered potential mediating factors and were included in the third level of analysis. A 
TABLE 2. Description of sample in terms of demographic, socioeconomic, and behavioral characteristics, Pelotas, Brazil, 2006 ${ }^{a}$

\begin{tabular}{|c|c|c|}
\hline Variable & $\begin{array}{l}\text { Mothers at time } \\
\text { of their own birth }\end{array}$ & $\begin{array}{l}\text { Mothers at time of } \\
\text { delivery of offspring }\end{array}$ \\
\hline Mean $(\mathrm{SD})^{\mathrm{b}}$ maternal age at delivery (years) & $25.3(6.35)$ & $18.4(1.90)$ \\
\hline Adolescent mother ( $<20$ years) (yes versus no) & $152(19.1 \%)$ & $577(72.7 \%)$ \\
\hline Maternal nonwhite skin color (yes versus no) & $166(21.0 \%)$ & $188(24.1 \%)$ \\
\hline Mean (SD) maternal height (centimeters, cm) & $155.5(5.80)$ & $159.5(6.12)$ \\
\hline Maternal height less than $150 \mathrm{~cm}$ (yes versus no) & $100(12.7 \%)$ & $37(5.0 \%)$ \\
\hline Mean (SD) maternal prepregnancy weight (kilograms, kg) & $55.0(9.13)$ & $56.3(9.86)$ \\
\hline Maternal prepregnancy weight $<50 \mathrm{~kg}$ (yes versus no) & $202(31.0 \%)$ & $155(26.8 \%)$ \\
\hline Maternal low educational level $<8$ years (yes versus no) & $630(79.5 \%)$ & $439(56.1 \%)$ \\
\hline \multicolumn{3}{|l|}{ Monthly family income (tertile) } \\
\hline First & $354(44.6 \%)$ & $259(34.0 \%)$ \\
\hline Second & $271(34.1 \%)$ & $243(32.0 \%)$ \\
\hline Third (wealthiest) & $169(21.3 \%)$ & $258(34.0 \%)$ \\
\hline \multicolumn{3}{|l|}{ Antenatal care (months) } \\
\hline 0 & $48(6.0 \%)$ & $7(1.0 \%)$ \\
\hline $1-3$ & $116(14.6 \%)$ & $39(5.0 \%)$ \\
\hline $4-6$ & $279(35.3 \%)$ & $144(18.5 \%)$ \\
\hline$\geq 7$ & $349(44.1 \%)$ & $585(75.5 \%)$ \\
\hline Primiparous (yes versus no) & $260(32.8 \%)$ & $794(100 \%)$ \\
\hline Smoking during pregnancy (yes versus no) & $344(43.3 \%)$ & $159(22.7 \%)$ \\
\hline Hypertensive disorder during pregnancy (yes versus no) & $47(6.0 \%)$ & $107(13.0 \%)$ \\
\hline Single mother (yes versus no) & $63(8.0 \%)$ & $302(38.0 \%)$ \\
\hline Mean (SD) offspring birth weight (grams) & $3133(476)$ & $3090(553)$ \\
\hline Offspring low birth weight (yes versus no) & $62(7.8 \%)$ & $83(10.5 \%)$ \\
\hline Offspring preterm status (yes versus no) & & $124(15.6 \%)$ \\
\hline Offspring small for gestational age status (yes versus no) & & $96(13.0 \%)$ \\
\hline \multicolumn{3}{|l|}{ Offspring sex } \\
\hline Male & & $413(52.0 \%)$ \\
\hline Female & $794(100 \%)$ & $381(48.0 \%)$ \\
\hline
\end{tabular}

a Data are numbers and percentages unless otherwise stated.

b SD, standard deviation.

FIGURE 2. Adjusted offspring mean birth weight and $95 \%$ confidence interval by maternal birth weight categories ( $P$ value for trend $<0.001$ ), Pelotas, Brazil, 2006

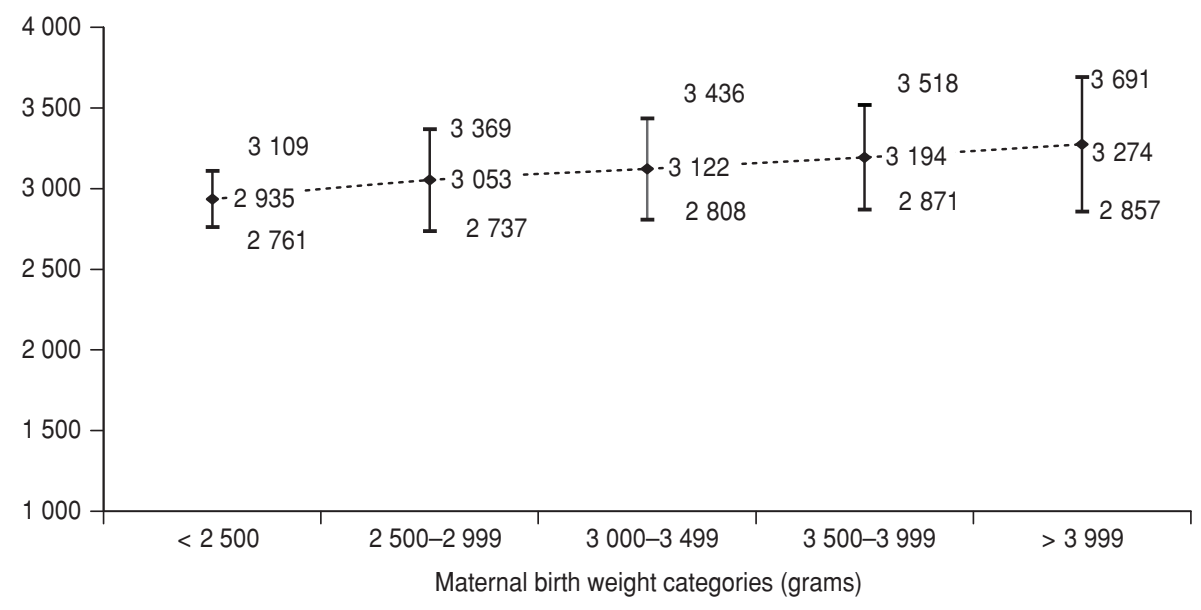

variable was considered a mediating factor if the strength of the association between the exposure and the outcome lessened when adjusted for the presumed mediator (23). All analyses were performed with STATA ${ }^{\circledR} 9.2$ (Stata Corporation, College Station, Texas).

\section{Quality control}

In 2001 and 2004, quality control included training for fieldworkers and the repetition of around 5\% of the interviews by a fieldwork supervisor. In addition, data were coded daily by interviewers and reviewed by the supervisor. All interviewers had completed at least a secondary school education. Interviewer training included general orientation, reading of the questionnaire and fieldwork manual, detailed discussion of each question, and questionnaire administration among the trainees and later with mothers from outside the cohort. Specific anthropometry techniques were practiced until all interviewers were performing measurements correctly. About twice the number of interviewers necessary for each visit was included in the training program. Interviewer selection was based on performance evaluation during training. Double data entry allowed for correction of possible entry errors.

\section{Ethical issues}

Verbal informed consent was obtained in all phases of the 1982 Birth Cohort Study. In 2001, parous women gave their verbal consent before the interview. For the perinatal study of the 2004 cohort, written consent was obtained.

\section{RESULTS}

Characteristics for both generations at birth are presented in Table 2. Compared with grandmothers, mothers were on average 4 centimeters $(\mathrm{cm})$ taller, were $1 \mathrm{~kg}$ heavier, and gained $1 \mathrm{~kg}$ more weight during pregnancy. Smoking during pregnancy decreased in the mother's generation. The overall prevalence of maternal LBW was $7.8 \%$, whereas in their offspring it was $10.5 \%$. The prevalences of preterm birth and SGA status in the offspring were $15.6 \%$ and $13 \%$, respectively.

Crude and adjusted positive linear associations between categories of maternal birth weight and offspring birth weight were found (Figure 2). For example, mothers who weighed between 2500 and $2999 \mathrm{~g}$ at birth delivered newborns who weighed on average $3053 \mathrm{~g}$ (95\% confidence interval (CI) 2 737-3 $369 \mathrm{~g}$ ), whereas those who weighed more than $3999 \mathrm{~g}$ at birth delivered heavier newborns (3 274 g on average, 95\% CI 2 857$3691)$. The Pearson correlation coefficient between maternal and infant birth weight was $0.18(P<0.001)$. The effect of maternal birth weight on other outcomes studied (LBW, preterm birth, and SGA) was similar to its effect on mean birth weight. Thus, there was a significant increasing trend in the prevalence of off- 
spring's LBW as maternal birth weight decreased. The same pattern was observed for offspring's preterm birth and SGA prevalence (Table 3).

Linear regression showed an association between maternal and offspring birth weights. In crude analysis, an increase of $100 \mathrm{~g}$ in the mothers' birth weight predicted an increase of $21 \mathrm{~g}$ in their infants' birth weight $(95 \%$ CI 13.0 $29.0 \mathrm{~g}, P<0.001)$. This association remained after adjustment for confounders.

Table 4 shows the crude and adjusted PRs for delivering a LBW, preterm, or SGA offspring according to maternal LBW. In crude analyses, LBW mothers were more than twice as likely as nonLBW mothers to have LBW offspring. LBW mothers were almost twice as likely as non-LBW mothers to give birth to a preterm or a SGA offspring.

The association between maternal and offspring LBW, preterm, and SGA status remained after adjustment for possible confounding factors (PR 2.28 (95\% CI 1.34-3.89), $P=0.002)$, (PR 1.78 (95\% CI 1.12-2.81), $P=0.01)$, and (PR 1.93 (95\% CI 1.14-3.26), $P=0.01$ ), respectively (Table 4). Because the variables infant sex, family income change, prenatal care, and maternal education were significant at the 0.2 level when evaluating maternal LBW and infant LBW, they were retained in the model. Yet, in the model of maternal LBW and offspring preterm birth, the variables family income change, prenatal care, maternal education, and SGA status were maintained. On the other hand, infant sex, maternal skin color, smoking, and adolescent status were retained in the model of maternal LBW and offspring SGA status.

TABLE 3. Offspring outcome by maternal birth weight, Pelotas, Brazil, 2006

\begin{tabular}{|c|c|c|c|c|c|c|}
\hline \multirow{3}{*}{$\begin{array}{l}\text { Maternal birth weight } \\
\text { (grams) }\end{array}$} & \multicolumn{6}{|c|}{ Offspring outcome } \\
\hline & \multicolumn{2}{|c|}{ LBW $^{a}$} & \multicolumn{2}{|c|}{ Preterm } & \multicolumn{2}{|c|}{$\mathrm{SGA}^{\mathrm{b}}$} \\
\hline & $n^{c}$ & Percent & $n^{c}$ & Percent & $n^{\mathrm{c}}$ & Percent \\
\hline$<2500$ & 62 & 24.2 & 62 & 25.8 & 56 & 23.2 \\
\hline $2500-2999$ & 238 & 12.6 & 238 & 17.2 & 221 & 14.5 \\
\hline $3000-3499$ & 305 & 8.9 & 305 & 15.1 & 283 & 12.4 \\
\hline $3500-3999$ & 166 & 6.0 & 166 & 11.5 & 154 & 9.7 \\
\hline > 3999 & 23 & 4.4 & 23 & 8.7 & 23 & 4.4 \\
\hline Total & 794 & 10.5 & 794 & 15.6 & 737 & 12.9 \\
\hline$P$ value for trend & \multicolumn{2}{|c|}{$<0.001$} & \multicolumn{2}{|c|}{0.01} & \multicolumn{2}{|c|}{0.01} \\
\hline
\end{tabular}

a LBW, low birth weight.

b SGA, small for gestational age status.

${ }^{c}$ Mother-offspring pairs with available data.

Potential mediating factors were evaluated, keeping in the models the variables that were retained when studying confounding and then adding to the models the maternal anthropometric characteristics and hypertensive diseases during pregnancy. The association between maternal LBW and offspring LBW and preterm birth remained significant (Table 4). Maternal height remained in the model between maternal LBW and infant LBW. No potential mediating factor remained in the model for preterm birth. In contrast, the risk of LBW mothers giving birth to SGA offspring became not significant when retaining maternal prepregnancy weight in the model (PR 1.40 (95\% CI 0.76-2.58), $P=0.3$ ).

\section{DISCUSSION}

This study showed that maternal birth weight was associated with offspring birth weight. Additionally, it demonstrated that maternal LBW was indepen- dently associated with offspring LBW, preterm birth, and SGA status. Our data suggest that the association between maternal LBW and infant SGA is at least partially mediated through the effects of maternal prepregnancy weight.

Two previous studies assessed the intergenerational transmission of fetal growth in developing countries $(18,36)$. However, our study is the first from a population-based prospective birth cohort study. Also, as the birth weights of the mothers were recorded by the research team in 1982, the possibility of recall bias was eliminated.

The findings of our study are consistent with others that assessed the intergenerational associations of birth weight. In general, available data have shown that, for each $100 \mathrm{~g}$ of additional maternal birth weight, offspring birth weight increased by 10-30 g (12, 15, 18, 36-41). Previous studies had found that LBW mothers were more likely to give birth to LBW babies (8-19), with odds ratios

TABLE 4. Crude and adjusted prevalence ratios for offspring low birth weight (LBW), preterm birth, and small for gestational age at birth (SGA) by maternal LBW status at birth, Pelotas, Brazil, 2006

\begin{tabular}{|c|c|c|c|c|c|c|c|c|c|}
\hline \multirow[b]{3}{*}{ Maternal status } & \multicolumn{9}{|c|}{ Offspring status } \\
\hline & \multicolumn{3}{|c|}{ LBW } & \multicolumn{3}{|c|}{ Preterm birth } & \multicolumn{3}{|c|}{ SGA } \\
\hline & $\mathrm{PRc}^{\mathrm{a}}$ & $P R a^{b}$ & $\mathrm{PRm}^{\mathrm{c}}$ & PRc & PRa & PRm & PRc & PRa & PRm \\
\hline \multicolumn{10}{|l|}{ LBW } \\
\hline No & Reference & Reference & Reference & Reference & Reference & Reference & Reference & Reference & Reference \\
\hline Yes & 2.60 & 2.28 & 2.15 & 1.75 & 1.78 & 1.78 & 1.90 & 1.93 & 1.40 \\
\hline$(95 \% \mathrm{Cl})^{\mathrm{d}}$ & $(1.59-4.28)$ & (1.34-3.89) & $(1.22-3.77)$ & $(1.11-2.76)$ & $(1.12-2.81)$ & $(1.12-2.81)$ & $(1.14-3.20)$ & $(1.14-3.26)$ & $(0.76-2.58)$ \\
\hline$P$ value & $<0.001$ & 0.002 & 0.01 & 0.02 & $0.01^{e}$ & $0.01^{\mathrm{e}}$ & 0.02 & 0.01 & 0.3 \\
\hline Number & 794 & 764 & 716 & 794 & 708 & 708 & 737 & 657 & 548 \\
\hline
\end{tabular}

a PRc, crude prevalence ratio.

b PRa adjusted prevalence ratio.

c PRm, mediated prevalence ratio, according to hierarchical model (Figure 1); variables were adjusted for others in the same or higher levels of the hierarchical model.

${ }^{\mathrm{d}} \mathrm{Cl}=$ confidence interval.

${ }^{\mathrm{e}}$ In model of preterm birth, SGA status was considered a possible confounding factor. SGA babies may be delivered preterm as a medical indication because of a higher risk of intrauterine death. 
(OR) ranging from 1.39 to 3.46 , which is consistent with our study (PR 2.50, 95\% CI 1.53-4.06). We also found that maternal LBW was associated with a 1.87-fold increased risk of preterm birth $(95 \% \mathrm{CI}$ 1.20-2.89), which is consistent with most $(13,16,20,42)$, although not all $(14,39)$, previous reports on this topic. Also, we found that LBW mothers had an increased risk of delivering an SGA baby (PR 1.74, 95\% CI 1.02-2.96), as other authors have reported $(10,21)$.

When exploring mediation between variables, prepregnancy weight was a mediating factor for the association between maternal LBW and offspring SGA. Part of the effect of maternal LBW on offspring SGA could be because LBW mothers are thinner than non-LBW mothers before pregnancy. In fact, mean prepregnancy weight among LBW mothers was $52.77 \mathrm{~kg}$ (standard deviation (SD) 8.41 $\mathrm{kg}$ ), and among non-LBW mothers it was $56.59 \mathrm{~kg}$ (SD $9.94 \mathrm{~kg})(P=0.01)$.

Our study has some methodologic limitations. First, the fact that mothers were not necessarily the first child could be a source of bias increasing the chance of detecting an association between maternal and child LBW. It is known that first-born children are usually lighter than second-born children, with small subsequent increases in birth weight (43). However, we did not find an association between maternal birth order and offspring birth weight (data not shown). Second, our data were limited to female cohort members up to 22 years old. In developing countries, pregnancy during adolescence is strongly linked to lower socioeconomic levels and adverse pregnancy outcomes are higher in this group, which may have overestimated the real prevalences $(24,34)$. Third, Brazilian studies investigating reliability of information from SINASC, as compared with data collected through research, detected kappa values around 0.94 for LBW and from 0.09 to 0.83 for preterm birth (44, 45). However, we compared information from SINASC for 4201 children born in Pelotas with information assessed by our research team in the 2004 birth cohort and found the LBW kappa $=0.98$ and the preterm birth kappa $=0.54$. The rate of preterm birth was underestimated by SINASC $(9.8 \%$ compared with $14.5 \%$ in our examination). Such misclassification is unlikely to be associated with maternal characteristics and is likely to have diluted the magnitude of the true association. As previously reported in Brazil (46) and in the United States of America (47), this finding is mainly due to misclassification of late preterm (gestational age 34-36 weeks) as term newborns. Last, we had no information on gestational age for the mother's birth. Therefore, it was not possible to assess whether maternal LBW was a consequence of preterm birth or impaired growth. This information could be useful to evaluate whether LBW is by itself a risk for adverse pregnancy outcomes or if there is an effect modification according to the underlying process.

Several plausible mechanisms have been proposed to explain the association between maternal LBW and adverse perinatal outcomes. First, among the extrinsic environmental exposures that persist across generations, it is recognized that parents pass socioeconomic characteristics on to their children (48). Compounding this scenario vis-à-vis the results from our current findings, poor women are likely to give birth to LBW babies. These babies will probably have a low socioeconomic status in adulthood, thus perpetuating adverse perinatal outcomes in the next generation. In our study, $43 \%$ of those women who were born in poverty were in the same situation at the time of their first pregnancy, accounting for higher prevalences of adverse perinatal outcomes (i.e., the prevalence of offspring LBW was $17 \%$ in the "always poor" group compared with $6 \%$ in the nonpoor/poor group, $11 \%$ in the poor/nonpoor group, and $8 \%$ in those who were never poor $(P=0.02))$.

Second, with regard to the adverse in utero exposures that stunt the mother's growth and possibly alter her metabolism, it has been proposed that reduced uterine size might contribute to fetal growth restriction and preterm birth (10). Although not measured in our study, it has been reported that uterine size is correlated to birth weight (4). On the other hand, others have proposed that abnormal phosphorylation of the insulin receptor, important in fetal growth, may contribute to altered reproductive function in LBW women (49).

Third, genetic attributes could manifest themselves similarly in mother and infant. With recent advances in human genetics, assessment of its contributions to human diseases has progressed signif- icantly, but the number of studies in preterm birth and intrauterine growth restriction is limited $(50,51)$. It is possible that increased availability of genomic studies may shed more light on possible etiologic mechanisms.

Although the evidence on intergenerational association of LBW and adverse perinatal outcomes is exhaustive, it is time to address the mediating mechanisms acting in this pathway. Further research should focus on illuminating the mediating factors to establish public health interventions aimed at breaking this cycle.

In conclusion, this study adds to the evidence that birth weight has an intergenerational component that acts independently of maternal socioeconomic and gestational factors. Knowledge of a woman's status at her birth would be useful to predict the outcome of her pregnancies. Moreover, the intermediate pathway of determination by maternal mediating factors opens a promising window of opportunity for preventive actions to reduce LBW and SGA rates, especially in developing countries such as Brazil, where SGA (a marker of intrauterine growth restriction) is the main determinant of LBW (52). From a public health perspective, the results of our study indicate that, in populations with similar socioeconomic, behavioral, and biological characteristics, preventive strategies should focus on promoting an adequate prepregnancy weight in women who were born LBW to stop the intergenerational transmission of adverse perinatal effects.

Acknowledgments. This analysis was supported by the Wellcome Trust initiative entitled Major Awards for Latin America on Health Consequences of Population Change. Earlier phases of the 1982 cohort study were funded by the International Development Research Center (Canada), the World Health Organization (Department of Child and Adolescent Health and Development, and Human Reproduction Programme), the Overseas Development Administration (United Kingdom), the United Nations Development Fund for Women, the National Program for Centers of Excellence (Brazil), the National Research Council (Brazil), and the Ministry of Health (Brazil). The authors thank the anonymous reviewers for their many constructive comments. 


\section{REFERENCES}

1. Barker DJP. Mothers, babies and health in later life. Edinburgh, Scotland, UK: Churchill Livingstone; 1998.

2. Ekholm K, Carstensen J, Finnstrom O, Sydsjo G. The probability of giving birth among women who were born preterm or with impaired fetal growth: a Swedish populationbased registry study. Am J Epidemiol. 2005; 161(8):725-33.

3. Hack M, Flannery DJ, Schluchter M, Cartar L, Borawski E, Klein N. Outcomes in young adulthood for very-low-birth-weight infants. N Engl J Med. 2002;346(3):149-57.

4. Ibañez L, Potau N, Enriquez G, de Zegher F. Reduced uterine and ovarian size in adolescent girls born small for gestational age. Pediatr Res. 2000;47(5):575-7.

5. Ibañez L, Potau N, Ferrer A, RodriguezHierro F, Marcos MV, de Zegher F. Reduced ovulation rate in adolescent girls born small for gestational age. J Clin Endocrinol Metab. 2002;87(7):3391-3.

6. Lapidus L, Andersson SW, Bengtsson C, Bjorkelund C, Rossander-Hulthen L, Lissner L. Weight and length at birth and their relationship to diabetes incidence and all-cause mortality-a 32-year follow-up of the population study of women in Gothenburg, Sweden. Prim Care Diabetes. 2008;2(3):127-33.

7. Dempsey JC, Williams MA, Luthy DA, Emanuel I, Shy K. Weight at birth and subsequent risk of preeclampsia as an adult. Am J Obstet Gynecol. 2003;189(2):494-500.

8. Klebanoff MA, Graubard BI, Kessel SS, Berendes HW. Low birth weight across generations. J Am Med Assoc. 1984;252(17):2423-7.

9. Klebanoff MA, Mills JL, Berendes HW. Mother's birth weight as a predictor of macrosomia. Am J Obstet Gynecol. 1985;153(3):253-7.

10. Klebanoff MA, Yip R. Influence of maternal birth weight on rate of fetal growth and duration of gestation. J Pediatr. 1987;111(2):287-92.

11. Klebanoff MA, Meirik O, Berendes HW. Second-generation consequences of small-fordates birth. Pediatrics. 1989;84(2):343-7.

12. Emanuel I, Filakti H, Alberman E, Evans SJ. Intergenerational studies of human birthweight from the 1958 birth cohort. 1. Evidence for a multigenerational effect. Br J Obstet Gynaecol. 1992;99(1):67-74.

13. Sanderson M, Emanuel I, Holt VL. The intergenerational relationship between mother's birthweight, infant birthweight and infant mortality in black and white mothers. Paediatr Perinat Epidemiol. 1995;9(4):391-405.

14. Klebanoff MA, Schulsinger C, Mednick BR, Secher NJ. Preterm and small-for-gestationalage birth across generations. Am J Obstet Gynecol. 1997;176(3):521-6.

15. Coutinho R, David RJ, Collins JW Jr. Relation of parental birth weights to infant birth weight among African Americans and whites in Illinois: a transgenerational study. Am J Epidemiol. 1997;146(10):804-9.

16. Emanuel I, Leisenring W, Williams MA, Kimpo C, Estee S, O'Brien W, et al. The Washington State Intergenerational Study of Birth Outcomes: methodology and some comparisons of maternal birthweight and infant birthweight and gestation in four ethnic groups. Paediatr Perinat Epidemiol. 1999;13(3):352-69.

17. Collins JW Jr., David RJ, Prachand NG, Pierce ML. Low birth weight across generations. Matern Child Health J. 2003;7(4):229-37.

18. Veena SR, Kumaran K, Swarnagowri MN, Jayakumar MN, Leary SD, Stein CE, et al. Intergenerational effects on size at birth in South India. Paediatr Perinat Epidemiol. 2004; 18(5):361-70.

19. Jaquet D, Swaminathan S, Alexander GR, Czernichow P, Collin D, Salihu HM, et al. Significant paternal contribution to the risk of small for gestational age. Br J Obstet Gynaecol. 2005;112(2):153-9.

20. De B, Lin S, Lohsoonthorn V, Williams MA. Risk of preterm delivery in relation to maternal low birth weight. Acta Obstet Gynecol Scand. 2007;86(5):565-71.

21. Simon DM, Vyas S, Prachand NG, David RJ, Collins JW Jr. Relation of maternal low birth weight to infant growth retardation and prematurity. Matern Child Health J. 2006;4:1-7.

22. Adams MM. Maternal birthweight and newborn status. Paediatr Perinat Epidemiol. 1999; 13(3):369-71.

23. Reime B, Ratner PA, Tomaselli-Reime SN, Kelly A, Schuecking BA, Wenzlaff P. The role of mediating factors in the association between social deprivation and low birth weight in Germany. Soc Sci Med. 2006;62(7):1731-44.

24. Kramer MS, Seguin L, Lydon J, Goulet L. Socio-economic disparities in pregnancy outcome: why do the poor fare so poorly? Paediatr Perinat Epidemiol. 2000;14(3):194-210.

25. Hypponen E, Power C, Smith GD. Parental growth at different life stages and offspring birthweight: an intergenerational cohort study. Paediatr Perinat Epidemiol. 2004;18(3):168-77.

26. Kramer MS. Determinants of low birth weight: methodological assessment and meta-analysis. Bull World Health Organ. 1987;65(5):663-737.

27. Doyle LW. Growth and respiratory health in adolescence of the extremely low-birth weight survivor. Clin Perinatol. 2000;27(2):421-32.

28. Ford GW, Doyle LW, Davis NM, Callanan C. Very low birth weight and growth into adolescence. Arch Pediatr Adolesc Med. 2000; 154(8):778-84.

29. Hack M, Weissman B, Borawski-Clark E. Catch-up growth during childhood among very low-birth-weight children. Arch Pediatr Adolesc Med. 1996;150(11):1122-9.

30. Powls A, Botting N, Cooke RW, Pilling D, Marlow N. Growth impairment in very low birthweight children at 12 years: correlation with perinatal and outcome variables. Arch Dis Child Fetal Neonatal Ed. 1996;75(3):F152-7.

31. Saigal S, Stoskopf BL, Streiner DL, Burrows E. Physical growth and current health status of infants who were of extremely low birth weight and controls at adolescence. Pediatrics. 2001;108(2):407-15.

32. Hack M, Schluchter M, Cartar L, Rahman M, Cuttler L, Borawski E. Growth of very low birth weight infants to age 20 years. Pediatrics. 2003;112(1 Pt 1):e30-8.

33. Victora CG, Barros FC, Lima RC, Behague DP, Gonçalves H, Horta BL, et al. The Pelotas birth cohort study, Rio Grande do Sul, Brazil, 1982-2001. Cad Saude Publica. 2003;19(5): 1241-56.

34. Gigante DP, Victora CG, Gonçalves H, Lima RC, Barros FC, Rasmussen KM. Risk factors for childbearing during adolescence in a population-based birth cohort in southern Brazil. Rev Panam Salud Publica. 2004;16(1):1-10.

35. Barros AJ, da Silva dos Santos I, Victora CG, Albernaz EP, Domingues MR, Timm IK, et al. The 2004 Pelotas birth cohort: methods and description. Rev Saude Publica. 2006;40(3): 402-13.

36. Ramakrishnan U, Martorell R, Schroeder DG, Flores R. Role of intergenerational effects on linear growth. J Nutr. 1999;129(2S Suppl): 544S-9S.

37. Alberman E, Emanuel I, Filakti H, Evans SJ. The contrasting effects of parental birthweight and gestational age on the birthweight of offspring. Paediatr Perinat Epidemiol. 1992; 6(2):134-44.

38. Lumey LH. Decreased birthweights in infants after maternal in utero exposure to the Dutch famine of 1944-1945. Paediatr Perinat Epidemiol. 1992;6(2):240-53.

39. Magnus P, Bakketeig LS, Skjaerven R. Correlations of birth weight and gestational age across generations. Ann Hum Biol. 1993;20(3): 231-8.

40. Skjaerven R, Wilcox AJ, Oyen N, Magnus P. Mothers' birth weight and survival of their offspring: population based study. Br Med J. 1997;314(7091):1376-80.

41. Emanuel I, Kimpo C, Moceri V. The association of maternal growth and socio-economic measures with infant birthweight in four ethnic groups. Int J Epidemiol. 2004;33(6):1236-42.

42. Simon DM, Vyas S, Prachand NG, David RJ Collins JW Jr. Relation of maternal low birth weight to infant growth retardation and prematurity. Matern Child Health J. 2006;10(4): 321-7.

43. Kramer MS. Intrauterine growth and gestational duration determinants. Pediatrics. 1987; 80(4):502-11.

44. Silva AA, Ribeiro VS, Borba AF Jr., Coimbra LC, Silva RA. Evaluation of data quality from the information system on live births in 19971998. Rev Saude Publica. 2001;35(6):508-14.

45. Theme Filha MM, Gama SG, Cunha CB, Leal Mdo C. Reliability of birth certificate data in Rio de Janeiro, Brazil, 1999-2001. Cad Saude Publica. 2004;20 Suppl 1:S83-91.

46. Barros FC, Victora CG, Barros AJ, Santos IS, Albernaz E, Matijasevich A, et al. The challenge of reducing neonatal mortality in middle-income countries: findings from three Brazilian birth cohorts in 1982, 1993, and 2004. Lancet. 2005;365(9462):847-54

47. Davidoff MJ, Dias T, Damus K, Russell R, Bettegowda VR, Dolan S, et al. Changes in the gestational age distribution among U.S. singleton births: impact on rates of late preterm birth, 1992 to 2002. Semin Perinatol. 2006; 30(1):8-15.

48. Conley D, Strully KW, Bennett NG. The starting gate: birth weight and life chances. Berkeley: University of California Press; 2003. 
49. Ibañez L, de Zegher F, Potau N. Premature pubarche, ovarian hyperandrogenism, hyperinsulinism and the polycystic ovary syndrome: from a complex constellation to a simple sequence of prenatal onset. J Endocrinol Invest. 1998;21(9):558-66.

50. Walenkamp MJ, Wit JM. Single gene mutations causing SGA. Best Pract Res Clin Endocrinol Metab. 2008;22(3):433-46.
51. Menon R, Fortunato SJ, Thorsen P, Williams S. Genetic associations in preterm birth: a primer of marker selection, study design, and data analysis. J Soc Gynecol Investig. 2006; 13(8):531-41.

52. Kramer MS, Victora CG. Low birth weight and perinatal mortality. In: Semba RD, Bloem MW, eds. Nutrition and health in developing countries. Totowa, NJ: Humana Press; 2001. Pp. 57-69.

Manuscript received on 29 June 2008. Revised version accepted for publication on 19 January 2009.

RESUMEN Objetivos. Explorar la asociación entre el bajo peso al nacer (BPN) de las madres y los desenlaces perinatales adversos y discriminar entre los factores de confusión y de mediación de estas asociaciones en un estudio poblacional de una cohorte de nacimientos en el sur de Brasil.

El bajo peso al nacer de las madres y los desenlaces perinatales adversos: Estudio de la Cohorte de Nacimientos de 1982 en Pelotas, Brasil

Métodos. Se analizaron los datos de 794 mujeres participantes en el Estudio de la Cohorte de Nacimientos de 1982 en Pelotas con partos únicos exitosos hasta diciembre de 2004. El peso al nacer de las mujeres se registró en 1982. Las asociaciones entre las características de las madres y sus hijos se estimaron mediante la regresión de Poisson. Como factores de confusión se probaron características socioeconómicas, demográficas y psicosociales. Como factores de mediación se consideraron las características antropométricas de la madre y la hipertensión durante el embarazo.

Resultados. El incremento en $100 \mathrm{~g}$ en el peso al nacer de las madres predijo un aumento de $21 \mathrm{~g}$ en el peso al nacer de sus hijos (intervalo de confianza de 95\% [IC95\%]: $13,0$ a 29,0; $P<0,001)$. El BPN de las madres se asoció con el BPN de sus hijos (prevalencia $[P R]=2,28$; IC95\%: 1,34 a 3,89; $P=0,002)$, el nacimiento prematuro ( $P R=1,78$; IC95\%: 1,12 a 2,81); $P=0,01)$ y la baja talla para la edad gestacional (BTEG) $(\mathrm{PR}=1,93$; IC95\%: 1,14 a 3,26; $P=0,01)$. El peso materno durante el embarazo resultó un factor de mediación en una cadena causal que relacionó el BPN de las madres y la BTEG de los hijos.

Conclusiones. Los hijos de madres jóvenes nacidas con BPN tienen mayor probabilidad de presentar BPN, prematuridad y BTEG. Las estrategias de salud pública dirigidas a reducir la frecuencia del BPN son necesarias para reducir los desenlaces perinatales adversos en las siguientes generaciones. El papel como factor de mediación del peso durante el embarazo en las mujeres con BPN abre un camino promisorio para reducir la prevalencia de la BTEG en poblaciones similares.

Palabras clave Peso al nacer; estudios de cohortes; recién nacido de bajo peso; prematuro; recién nacido pequeño para la edad gestacional; Brasil. 